\title{
Soil moisture variation in relation to topography and land use in a hillslope catchment of the Loess Plateau, China
}

\author{
Yang Qiu, Bojie Fu*, Jun Wang, Liding Chen \\ Department of Systems Ecology, Research Center for Eco-Environmental Sciences, Chinese Academy of Sciences, P.O. BOX 2871, \\ Beijing 100085, People's Republic of China
}

Received 1 November 1999; revised 17 August 2000; accepted 5 October 2000

\begin{abstract}
The profile characteristics and the temporal dynamics of soil moisture variation were studied at 26 locations in Da Nangou catchment $\left(3.5 \mathrm{~km}^{2}\right)$ in the loess area of China. Soil moisture measurements were performed biweekly at five depths in the soil profile $(0-5,10-15,20-25,40-45$ and $70-75 \mathrm{~cm})$ from May to October 1998 using Delta-T theta probe. Soil moisture profile type and temporal variation type and their relationship to topography and land use were identified by detrended canonical correspondence analysis (DCCA) and correlation analysis. The profile distribution of time-averaged soil moisture content can be classified into three types i.e. decreasing-type, waving-type and increasing-type. The profile features of soil moisture (e.g. profile gradient and profile variability) are influenced by different environmental factors. The profile type of soil moisture is only attributed to land use while profile gradient and profile variability of soil moisture is mainly related to land use and topography (e.g. landform type and slope). The temporal dynamics of layer-averaged soil moisture content is grouped into three types including three-peak type, synchro-four-peak type and lagged-four-peak type. These types are controlled by topography rather than by land use. The temporal dynamic type of soil moisture shows significant correlation with relative elevation, slope, aspect, while temporal variance displays significant relation with slope shape. The mean soil moisture is related to both the profile and dynamics features of soil moisture and is controlled by both land use and topography (e.g. aspect, position, slope and relative elevation). The spatial variability of soil moisture across landscape varies with both soil depths and temporal evolution. (C) 2001 Elsevier Science B.V. All rights reserved.
\end{abstract}

Keywords: Soil moisture content; Spatial and temporal variation; Environmental factors; Detrended canonical correspondence analysis; Correlation analysis; The Loess Plateau of China

\section{Introduction}

Soil moisture is an important variable for understanding and predicting a range of hydrological processes including flooding, erosion, solute transport and land-atmosphere interactions. Soil moisture exhibits a high degree of spatial and temporal variability (Owe et al., 1982; Grayson et al., 1997). Both surface

\footnotetext{
* Corresponding author. Fax: +86-10-62923563.

E-mail address: bfu@mail.rcees.ac.cn (B. Fu).
}

soil moisture and subsoil moisture have profound effects on the above processes (Western and Grayson, 1998). For example, accumulation of soil water in the subsoil will lead to subsurface runoff, even if complete saturation does not occur (Burt and Butcher, 1985). While, many researches have studied the horizontal variation and temporal changes of soil moisture (Hawley et al., 1983; Nyberg 1996; Famiglietti et al., 1998; Western et al., 1998), little attention has been paid to the profile features of soil moisture (Loague, 1992; Li et al., 1999). 
There have been a number of recent papers indicating that land use (Fu et al., 2000), slope gradient (Moore et al., 1988), aspect (Western et al., 1999), curvature (Western et al., 1999), slope position and relative elevation (Crave and Gascuel-odux, 1997), soil properties (Reynolds, 1970a), mean soil moisture (Bell et al., 1980), precipitation (Famiglietti et al., 1998), solar radiation (Western et al., 1999) have influences on the distribution of soil moisture. A comprehensive knowledge of soil moisture variations in relation to land use and topography can provide a simple approach for subdivision of a watershed into spatial units with homogeneous hydrologic response (Hawley et al., 1983) and for the estimation of areal soil moisture from a limited number of sample locations (Grayson and Western, 1998) in distributed hydrologic modeling. However, it is difficult to identify the relative importance of these factors because of their mutual and multiple influence on soil moisture, and contradictory findings have appeared in the literature (Famiglietti et al., 1998; Western et al., 1999). Therefore, the relationships between soil moisture and land use and topography need to be studied in a variety of places and over a large range of scales. However, such study is rare though it is especially important on the Loess Plateau of China with distinct variation in topography (Zhuang, 1989; Yang et al., 1998; Fu et al., 1999, 2000; Fu and Chen, 2000). Moreover, no effort was made to investigate the temporal and spatial types of soil moisture content and their relations with environmental factors in this area.

Generally, regression and geostatistical analysis have been the main analytical tools for studies of relationships between soil moisture and environmental factors (Nyberg, 1996; Crave and Gascuel-Odux, 1997; Bárdossy and Lehmann, 1998; Western et al., 1998, 1999). However, these methods may not be suitable when large numbers of variables are involved. In such situations, other multivariate methods are recommended (Zhang and Oxley, 1994). Intrinsic methods such as principal component analysis (PCA), involving a single set of soil data, have been applied for soil studies (McBratney and Webster, 1981). However, extrinsic methods that relate patterns in one set of variables (environmental factors or predictors) to those in another set of variables (soil moisture) would improve the predictive power of interpolation techniques and thus soil moisture pattern. Extrinsic methods such as linear canonical correlation analysis (COR) and redundancy analysis (RDA) are all variants of the basic linear transformation. Although these linear methods may be successful, an alternative to the basic assumption that soil variables are systematically and monotonically related to environmental attributes has not been tested. Nonlinear methods such as canonical correspondence analysis (CCA), which are based on the non-monotonic Gaussian (bell-shaped) species response models, have been demonstrated to be more robust in extracting variation in species abundance in relation to the environment than linear models (Ter Braak, 1986; Zhang and Oxley, 1994). CCA highlights the main features of variation in a population in relation to the environment. CCA is a direct gradient ordination analytical method in which the axes are chosen with respect to the environmental attributes. This technique has been tried in soil-environment research (Odeh et al., 1991). However, in most of cases, the second axis of CCA may be the second-variant of the first axis, leading to the 'arch effect' or 'horseshoe effect' which reduces the efficiency of ordination (Hill and Gauch, 1980). Another nonlinear method, which has been applied in ecological studies but not yet tried in soil-environment research, is the Detrended Canonical Correspondence Analysis (DCCA) (Ter Braak, 1987; Qiu and Zhang, 2000). DCCA can remove the 'arch effect' and thus may improve the robustness of ordination.

In order to gain a better understanding of soil moisture variations in relation to land use and topography, we use DCCA and correlation analysis to analyze soil moisture data obtained from a hillslope catchment of the Loess Plateau of China. The objectives are: (a) to characterize the profile types as well as additional profile features of soil moisture content and the relationships between each of these profile features, and to understand the relative importance of each of the environmental factors (e.g. land use and topography) on profile features of soil moisture; (b) to quantify the temporal dynamic types and temporal variability of soil moisture content and the relationships between these two dynamics variables; and to analyze the relative roles of environmental attributes in controlling temporal dynamic characteristics of soil moisture content; (c) to explore mean soil moisture content 


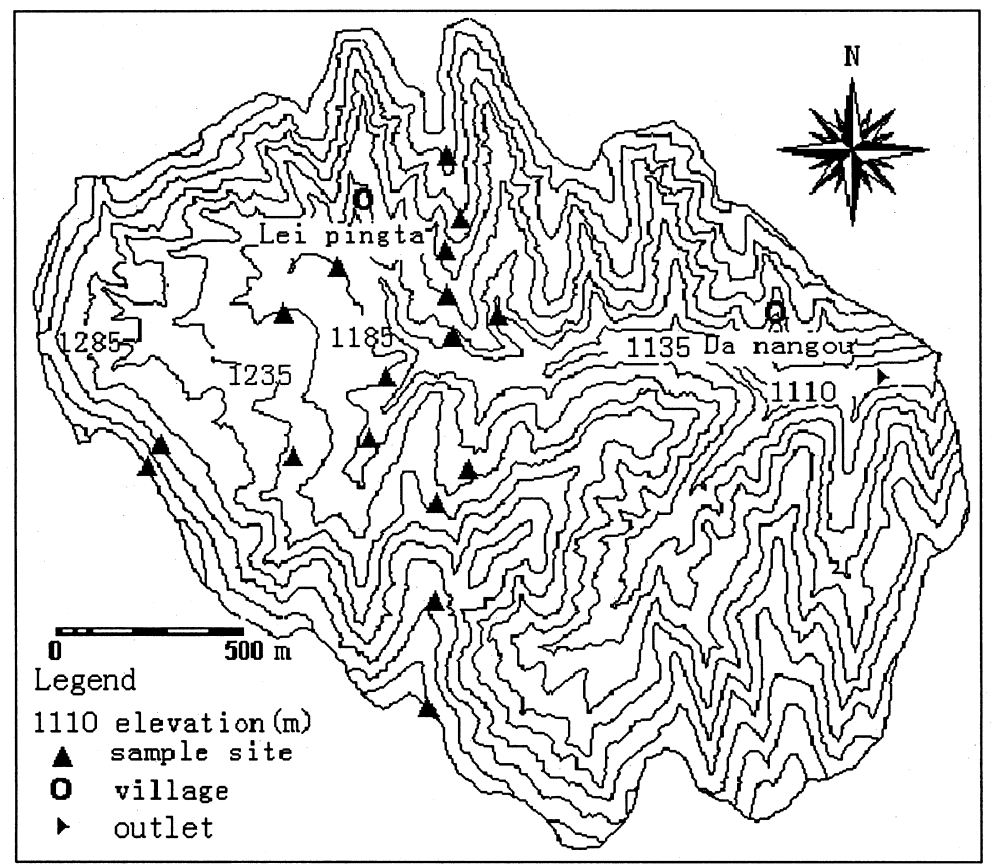

Fig. 1. Spatial distribution of sampling sites in the Da Nangou catchment with the contour interval of $25 \mathrm{~m}$.

and its relation with both the profile type and the temporal dynamics of soil moisture and to investigate the relative importance of environmental factors in influencing mean soil moisture content; (d) to quantify the spatial variation of soil moisture content across landscape.

\section{Study area}

The Da Nangou catchment $\left(36^{\circ} 53^{\prime} \mathrm{N}, 109^{\circ} 17^{\prime} \mathrm{E}\right)$ is situated on the middle part of the Loess Plateau in northern Shaanxi province in China. The catchment has an area of $3.5 \mathrm{~km}^{2}$ and an altitude between 1000 and $1350 \mathrm{~m}$. There are significant topographic variations with typical loess hill and gully landforms within the study area. Due to long-term human activity, natural vegetation has been destroyed. Land use types including slope cropland, fallowland, wasteland, shrubland, orchardland, intercropland and woodland consist of mosaic patterns. Crops are mainly potatoes (Solanum tuberosum), beans (Phaseolus valgaris), maize (Zea mays L.) and millet (Panicum miliaceum). The forest, artificial woods, is dominated by Locust trees (Robinia pseudoacacia L.). The wasteland is mainly covered by annuals such as sweet wormwood (Artemisia annua L.), annual fleabane (Erigeron annuus Pers.) and sandy needlegrass (Stipa glareosa p. Smirn). Littleleaf peashrub (C aragana microphylla) in shrubland and apple tree (Malus pumila mill) in orchard are present. Fallowland slowly came into being after cultivated plots were abandoned two and three years ago.

The region has a semiarid continental climate with an average annual temperature of $8.8^{\circ} \mathrm{C}$. Monthly mean temperatures range from $22.5^{\circ} \mathrm{C}$ in July to $-7^{\circ} \mathrm{C}$ in January. The average annual precipitation is $562 \mathrm{~mm}$ with great interannual variability. Sixty percent of the rainfall falls between July and September, while only $3 \%$ of precipitation falls as snow or rainfall between December and February when frozen soil conditions exist in the catchment. There are 159 frost-free days and an average of $2415 \mathrm{~h}$ of sunshine each year.

The soils, developing on wind-accumulated loess parent material, are thick at an average of 50-80 m. The most common soil in the catchment is loess with texture of fine silt and silt soil. It is weakly resistant to 


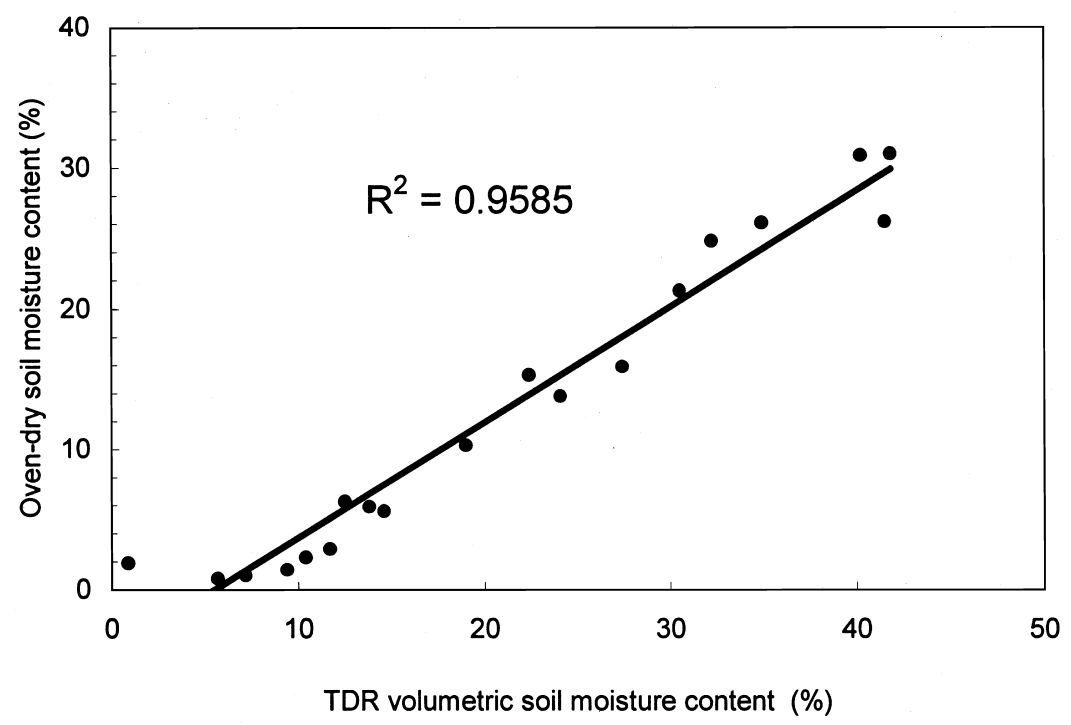

Fig. 2. Calibration of the TDR using regression analysis (solid line $=$ regression line).

erosion (Fu, 1989; Fu and Gulinck, 1994). The erosion rate is extremely high at about $10-12 \mathrm{~kg} / \mathrm{m}^{2} /$ year (Song et al., 1989).

\section{Methods}

\subsection{Soil moisture sampling}

According to different types of topographic regime and land use, a total of 26 sample sites were selected for measuring soil water content in the catchment (See Fig. 1). The land use type and six topographical factors including aspect, slope position, slope shape, landform type, slope degree, and elevation were recorded for each plot. Soil moisture data were obtained using Delta-T theta probe (Eijkelkamp Agrisearch Equipment, Netherlands) on 10 occasions during the growing season from May to October 1998 at approximately biweekly intervals. When measurements to use soil auger to the anticipated depth, four parallel steel rods (length $6 \mathrm{~cm}$, diameter $0.3 \mathrm{~cm}$, and spacing $2.5-3 \mathrm{~cm}$ ) were inserted vertically into the soil, and remained in position until the value displayed TDR was stable. At each sample point, five samples were taken to measure moisture content at five depths: $0-5,10-15,20-25,40-45$ and $70-75 \mathrm{~cm}$. Rainfall was recorded by an automatic datalogged raingauge located in the catchment, which was a total of $465.42 \mathrm{~mm}$ during the study period.

TDR was calibrated by comparison with gravimetric water content measurements from saturated soil water content to permanent wilting point, obtained from conventional oven-dry weights and multiplied by bulk density data. The regression equation is $Y=0.8243 X-0.0454, R^{2}=0.9585$, where $X$-soil water content using TDR, $Y$-soil water content using oven-dry method multiplied by soil bulk density (Fig. 2). Soil moisture data used below were based on this calibration.

\subsection{Calculations of variables}

Calculations of several variables used in this study are demonstrated as follows: suppose that soil moisture content of plot $i$, layer $j$ and sampling occasion $k$ is expressed as $M_{i, j, k}$. $N_{\mathrm{p}}$ is the number of plots and is 26 in this study; $N_{1}$ represents the number of sampling soil layer or soil depths and is 5 in this study; $N_{\mathrm{t}}$ is the number of sampling occasion and is 10 in this study.

1. Mean soil moisture content on plot $i\left(M_{i}\right)$

$$
M_{i}=\frac{1}{N_{\mathrm{l}} \times N_{\mathrm{t}}} \sum_{j=1}^{N_{\mathrm{l}}} \sum_{k=1}^{N_{\mathrm{t}}} M_{i, j, k}
$$


2. Mean soil moisture content at soil layer $j\left(M_{j}\right)$

$$
M_{j}=\frac{1}{N_{\mathrm{p}} \times N_{\mathrm{t}}} \sum_{i=1}^{N_{\mathrm{p}}} \sum_{t=1}^{N_{1}} M_{i, j, k}
$$

3. Mean soil moisture content in sampling occasion $k\left(M_{k}\right)$

$$
M_{k}=\frac{1}{N_{\mathrm{p}} \times N_{\mathrm{l}}} \sum_{i=1}^{N_{\mathrm{p}}} \sum_{j=1}^{N_{\mathrm{l}}} M_{i, j, k}
$$

4. Time-averaged soil moisture content on plot $i$ and at layer $j\left(M_{i, j}\right)$

$$
M_{i, j}=\frac{1}{N_{\mathrm{t}}} \sum_{k=1}^{N_{\mathrm{t}}} M_{i, j, k}
$$

5. Layer-averaged soil moisture content on plot $i$ and in sampling occasion $k\left(M_{i, k}\right)$

$$
M_{i, k}=\frac{1}{N_{1}} \sum_{j=1}^{N_{1}} M_{i, j, k}
$$

6. Profile variability of time-averaged soil moisture content on plot $i\left(\mathrm{VP}_{i,}\right)$

$\mathrm{VP}_{i, k}=\sqrt{\frac{N_{1} \sum_{j=1}^{N_{1}}\left(M_{i, j}\right)^{2}-\left(\sum_{j=1}^{N_{1}} M_{i, j}\right)^{2}}{N_{1}\left(N_{1}-1\right)}}$

7. Temporal variability of layer-averaged soil moisture on plot $i\left(\mathrm{VT}_{i}\right)$

$$
\mathrm{VT}_{i}=\sqrt{\frac{N_{\mathrm{t}} \sum_{k=1}^{N_{\mathrm{t}}}\left(M_{i, k}\right)-\left(\sum_{k=1}^{N_{\mathrm{t}}} M_{i, k}\right)}{N_{\mathrm{t}}\left(N_{\mathrm{t}}-1\right)}}
$$

8. Spatial variability of time-averaged soil moisture at soil layer $j\left(\mathrm{VS}_{j}\right)$

$$
\mathrm{VS}_{j}=\sqrt{\frac{N_{\mathrm{p}} \sum_{i=1}^{N_{\mathrm{p}}}\left(M_{i, j}\right)^{2}-\left(\sum_{i=1}^{N_{\mathrm{p}}} M_{i, j}\right)^{2}}{N_{\mathrm{p}}\left(N_{\mathrm{p}}-1\right)}}
$$

9. Spatial variability of layer-averaged soil moisture on sampling occasion $k\left(\mathrm{VS}_{k}\right)$

$$
\mathrm{VS}_{k}=\sqrt{\frac{N_{\mathrm{p}} \sum_{i=1}^{N_{\mathrm{p}}}\left(M_{i, k}\right)^{2}-\left(\sum_{i=1}^{N_{\mathrm{p}}} M_{i, k}\right)^{2}}{N_{\mathrm{p}}\left(N_{\mathrm{p}}-1\right)}}
$$

10. Profile gradient of time-averaged soil moisture on plot $i\left(\mathrm{G}_{i}\right)$

$$
G_{i}=\frac{M_{i, 5}-M_{i, 1}}{0.7}
$$

11. Relative elevation of plot $i\left(\mathrm{RE}_{i}\right)$ is defined as the elevation difference between the sample point $\left(\mathrm{E}_{i}\right)$ and the stream at the bottom of that hillslop (ES):

$$
\mathrm{RE}_{i}=\mathrm{E}_{i}-\mathrm{ES}
$$

\section{3. $D C C A$}

\subsubsection{Theory}

Suppose that for a survey with $n$ sites, $m$ variables and $q$ environmental attributes are determined. Let $Y$ be the data matrix of the soil moisture and $V$ be the matrix of environmental attributes; $y_{i k}$, an element of $Y$, is the value of variable $k$ at site $i$, and $v_{i j}$, an element of $V$, is the value of environmental attribute $j$ at site $i$. In the procedure, which assumes as Gaussian response curve, an ordination axis is constructed such that the data will optimally if a Gaussian response curve defined by the function:

$E\left(y_{i k}\right)=c_{k} \exp \left[-0.5\left(x_{i}-u_{k}\right)^{2} t_{k}^{-2}\right]$

Where $E\left(y_{i k}\right)$ is the expected value of $y_{i k}$ which has score $x_{i}$ on the ordination axis; $c_{k}$ is the maximum parameter for variable $k$; $u_{k}$ is the optimum or the value of $x$ for which the maximum is attained for 
variable $k$; and $t_{k}$ is the level of tolerance for variable $k$.

In ecological studies, ordination of species data using Gaussian models may contain a direct gradient analysis in which the ordination axes are related to the environmental attributes. This is usually done by multiple regression analysis of the site scores on environmental attributes using the following equation:

$x_{i}=b_{0}+\sum_{j=1}^{q} b_{j} v_{i j}$

Direct gradient analysis in which the regression equation is incorporated into the ordination algorithm may be used to simultaneously carry out ordination and multiple regression of the resulting axes on the environmental attributes. DCCA is such direct gradient analysis based on a unimodal model.

A robust and computationally simpler procedure (i.e. weighted averaging) is used to DCCA estimation of the parameter values of $c_{k}, u_{k}$ and $t_{k}$. The weighted averaging need not conform to the stringent assumptions of the Gaussian model (Ter Braak, 1985). The transition formulae that link Gaussian ordination to DCCA are:

$$
\begin{aligned}
& \lambda u_{k}=\sum_{i=1}^{n} \frac{y_{i k} x_{i}}{y_{+k}} \\
& x_{i}^{*}=\sum_{k=1}^{m} \frac{y_{i k} u_{k}}{y_{i+}} \\
& b=\left(V^{\prime} R V\right)^{-1} V^{\prime} R_{x^{*}} \\
& x=V b
\end{aligned}
$$

Where $y_{+k}$ and $y_{i+}$ are the attribute and site totals, respectively; $R$ is a diagonal $n \times n$ matrix with $y_{i+}$ as the $(i, i)$ th element; $V=\left\{v_{i j}\right\}$ is an $n \times(q+1)$ matrix of environmental data and a column of ones; and $b, x$ and $x^{*}$ are column vectors: $b=\left(b_{0}, b_{1}, \ldots, b_{q}\right)^{\prime}, x=$ $\left(x_{1}, \ldots, x_{n}\right)^{\prime}$ and $x^{*}=\left(x_{1}^{*}, \ldots, x_{n}^{*}\right)^{\prime} . \lambda$ is the eigen value (Ter Braak, 1986).

\subsubsection{Data sets prepared}

The qualitative data have to be coded before DCCA (Ter Braak, 1988; Qiu and Zhang, 2000). The aspect is recorded by degree from the north, and classified into 4 categories: 1 represents south $\left(135-225^{\circ}\right) ; 2$ represents west $\left(225-315^{\circ}\right) ; 3$ east $\left(45-135^{\circ}\right) ; 4$ north $\left(315-45^{\circ}\right)$. The slope position is coded into 3 types: 1 represents downslope; 2 middle slope; and 3 upslope. The slope shape is divided into 3 types: 1 represents convex; 2 straight; and 3 concave. The landform is divided into 3 types: 1 represents slope land; 2 hilltop; and 3 Terrace. Land use is coded into 7 types: 1 represents shrub land; 2 wood land; 3 orchard land; 4 intercropping land; 5 waste land; 6 fallow land; and 7 crop land. The slope is expressed by measurement values. The relative elevation $\left(\mathrm{RE}_{i}\right)$ is calculated as above.

The data matrices of soil moisture content and the environmental factors are necessary for DCCA (Ter Braak, 1988; Qiu and Zhang, 2000). The data matrix of environmental factors is $P \times N$, where $P$ is the number of environmental factors, and $N$ represents the number of plots (i.e. $N_{\mathrm{p}}$ as described above). In this paper, $P$ is 7 , including aspect, slope position, slope shape, landform type, land use, slope degree, relative elevation, while $N$ is 26 . In order to analyze the profile structure and the dynamics structure of the soil moisture content separately, two data matrixes of $P \times N$ are required, respectively, both having the same value of $N$ (number of plots, $N_{\mathrm{p}}$ ). Whereas, the $P$ of data matrix of profile structure means the number of soil profile layers (i.e. $N_{\mathrm{l}}, 5$ in this study), and the soil moisture content is time-averaged $\left(M_{i, j}\right)$ calculated from Eq. (4). The $P$ of data matrix of the dynamics structure represents the number of measurement occasions (i.e. $N_{\mathrm{t}}, 10$ in this study), and the soil moisture content is layer-averaged $\left(M_{i, k}\right)$ calculated from Eq. (5).

A ForTRAN program (CANOCO), written by Ter Braak (1988), was used for all ordination analysis. A bi-plot which shows the distribution of sites on two ordination axes together with vectors which indicated the amount of variation explained by each environmental variable were produced. Environmental variables were related to ordination site scores using Spearman's rank correlation coefficients. Using CANOCO and combining these two data matrixes of profile and dynamics structure of soil moisture content to the data matrix of environmental factors separately, we can obtain two sets of ordinate values of each plot and each environmental factor as the basis of further analyses respectively. 


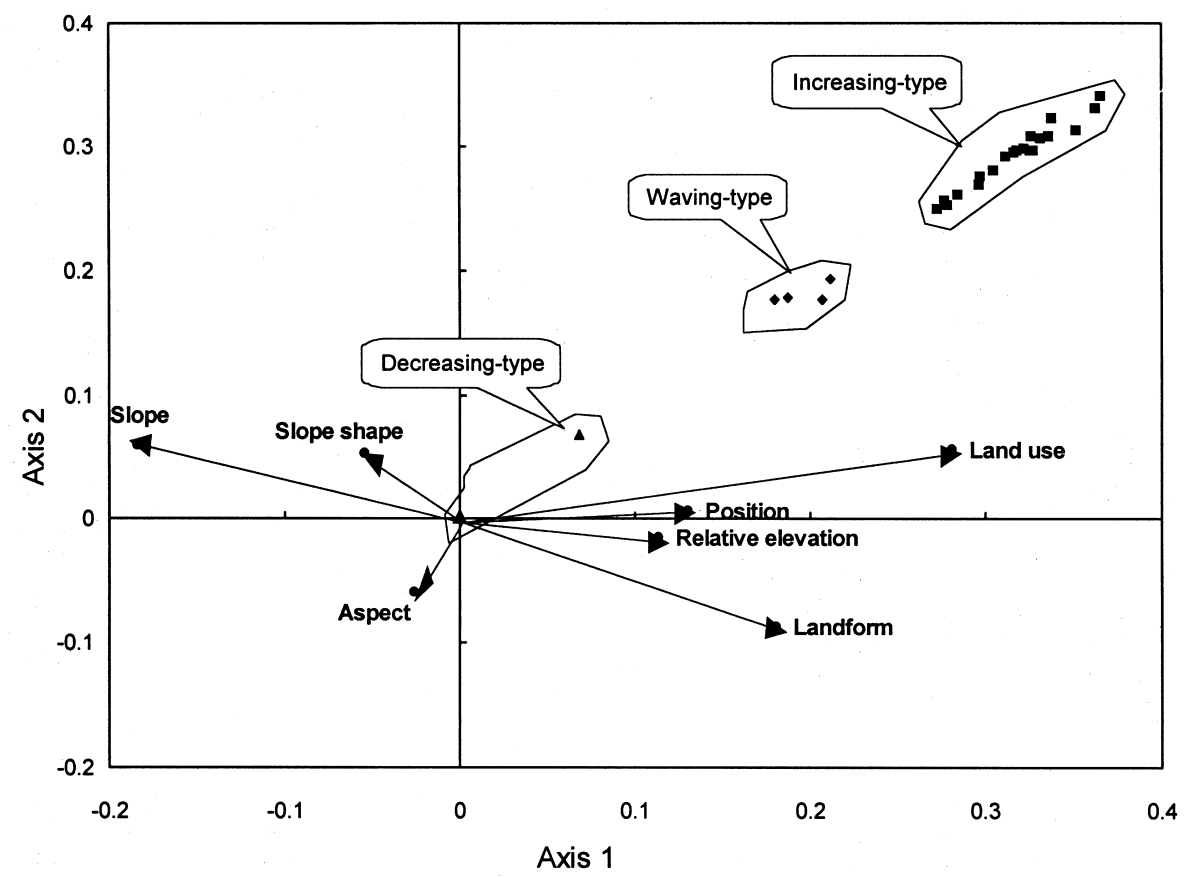

Fig. 3. Ordination diagram resulting from DCCA on time-averaged soil moisture with environmental attributes.

\section{Results}

\subsection{Profile distribution of soil moisture and its relation to environmental factors}

\subsubsection{DCCA ordination diagram and its interpretation}

The result of DCCA can be displayed in an ordination diagram in which scores of sites are represented by points. Scores for the environmental attributes are indicated as arrows (Fig. 3). In interpreting the ordination diagram, each of the arrows representing an environmental attribute gives a direction or axis of variation in relation to the two canonical ordination axes (usually the first two axes that are extracted from soil moisture variables as linear combinations of environmental attributes). The arrows can be extended in both directions and perpendicular lines drawn (or by imagined projection) onto it from the points of sites. The order in which the projected points relate to the environmental axis indicates the relative importance or ranking of the weighted means of sites with respect to the attribute. The weighted mean of a site shows approximately its optimum along the environmental attribute gradient.

The arrow length for each environmental attribute quantifies the rate of change in the weighted means of sites as indicated in the ordination diagram. The length, therefore, indicates how variations in measured sites differ along the environmental gradients. This also means that environmental attributes that are highly correlated with an ordination axis are represented by longer arrows that are closer to the axis than those for the less important environmental attributes.

The DCCA ordination diagram (Fig. 3) illustrates, in an exploratory manner, the relationships between the sites and the environmental attributes. Clearly, three types of profile structure of time-averaged soil moisture content $\left(M_{i, j}\right)$ shown in the ordinal diagram of DCCA (Fig. 3) are closely related to the first two axes mainly representing land use trend. This is not surprising the fact that those points of the increasingtype (Fig. 4c and d) are at the end of the land use arrow, those of waving-type (Fig. 4b) are located in the middle part of the arrow and the decreasing-types (Fig. 4a) are close to the origin of arrow. This implies 

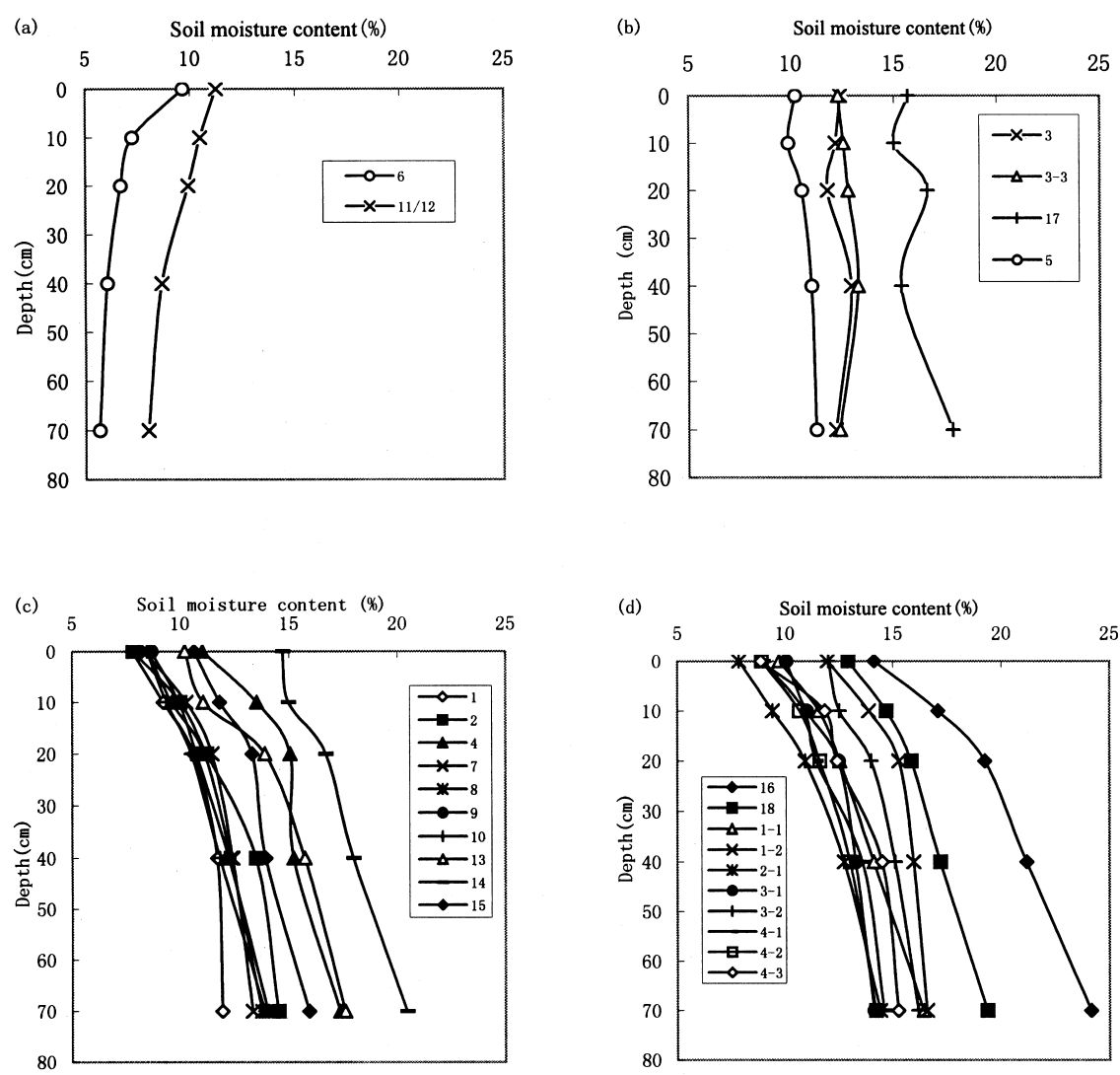

Fig. 4. Profile distribution diagrams of time-averaged soil moisture.

that decreasing-type only emerges on sites of shrub land and woodland, waving-type was found on sites of orchard and increasing-type mainly on sites of cropland and fallow land (See Table 1). In addition, the site points of these three profile types exhibit weak and positive relation with slope position, landform type and relative elevation, and weak and negative relation with aspect and slope gradient. However, slope shape only accounts for very low variation in the profile distribution of time-averaged soil moisture. This is consistent with the results from correlation analysis (Table 3).

\subsubsection{General features of profile distribution of time- averaged soil moisture content}

Among three profile types of time-averaged soil moisture identified from DCCA ordination diagram (Fig. 3), the decreasing-type occurs on 2 of the 26 sites, and it shows a decreasing trend of soil moisture content with decreasing soil depth (see also Table 2 and Fig. 4a). Waving-type was found on four sites, and soil moisture displaying a fluctuating trend with increasing of depth (see Table 2 and Fig. 4b). Its profile distribution characteristics are similar to that of decreasing-type. Soil moisture decreases with increasing of depth in the topsoil $(0-10 \mathrm{~cm})$, thereafter begin to undulate with increasing of soil depth. The third type, increasing-type exhibiting an increasing trend was found on 20 of the 26 sites (See Table 2, Fig. $4 \mathrm{c}$ and d). This may be accounted for the strong evaporation and small amount of precipitation in studied area.

There are considerably differences in characteristics of soil moisture content among three types. Mean soil moisture content of individual plot $\left(M_{i}\right)$ shows following sequence: decreasing-type (average $8.37 \%)<$ waving-type $(12.92 \%)<$ increasing-type $(13.03 \%)$ (Table 2). The main reason is difference 
Table 1

Topographical attributes and the land use types of sampling plots

\begin{tabular}{|c|c|c|c|c|c|c|c|}
\hline Plot & Aspect & Slope position & Slope shape & Landform types & Slope gradient $\left(^{\circ}\right)$ & Relative elevation (m) & Land use type \\
\hline 1 & South & Up & Straight & Hilltop & 15 & 126 & Crop \\
\hline 2 & South & Up & Straight & Slope & 15 & 122 & Fallow \\
\hline 3 & East & Down & Straight & Slope & 40 & 42 & Waste \\
\hline 4 & North & Down & Straight & Slope & 30 & 31 & Crop \\
\hline 5 & South & Middle & Convex & Terrance & 8 & 57 & Orchard \\
\hline 6 & West & Middle & Straight & Slope & 30 & 72 & Forest \\
\hline 7 & South & Up & Straight & Slope & 30 & 97 & Crop \\
\hline 8 & West & Middle & Convex & Slope & 15 & 104 & Crop \\
\hline 9 & East & Middle & Convex & Slope & 30 & 119 & Crop \\
\hline 10 & West & Up & Convex & Slope & 18 & 177 & Waste \\
\hline $11 / 12$ & North & Up & Straight & Slope & 15 & 204 & Shrub \\
\hline 13 & North & Middle & Straight & Terrance & 5 & 93 & Intercropping \\
\hline 14 & North & Middle & Straight & Slope & 8 & 94 & Forest \\
\hline 15 & North & Up & Concave & Slope & 5 & 128 & Crop \\
\hline 16 & North & Middle & Straight & Terrance & 1 & 76 & Crop \\
\hline 17 & North & Down & Convex & Slope & 18 & 56 & Orchard \\
\hline 18 & North & Down & Straight & Slope & 15 & 39 & Crop \\
\hline $1-1$ & South & Up & Straight & Hilltop & 5 & 157 & Fallow \\
\hline $1-2$ & West & Down & Straight & Slope & 40 & 37 & Fallow \\
\hline $2-1$ & West & Up & Convex & Hilltop & 5 & 243 & Fallow \\
\hline $3-1$ & North & Up & Concave & Hilltop & 1 & 219 & Fallow \\
\hline $3-2$ & North & Middle & Convex & Slope & 12 & 103 & Crop \\
\hline $3-3$ & North & Down & Straight & Slope & 10 & 26 & Orchard \\
\hline $4-1$ & East & $\mathrm{Up}$ & Convex & Slope & 25 & 138 & Crop \\
\hline $4-2$ & East & Middle & Convex & Slope & 8 & 113 & Crop \\
\hline $4-3$ & East & Middle & Concave & Slope & 19 & 88 & Crop \\
\hline
\end{tabular}

in transpiration of plants such as locust trees and littleleaf pearshrubs $>$ fruit trees and small shrubs $>$ crops and annuals. The profile gradient of soil water $\left(G_{i}\right)$ shows a negative value $(-5.18)$ on sites of decreasing-type further proving that soil moisture decreases with depth. Though the profile gradient of soil water is positive (1.36) on sites of waving-type, it is less than that (8.31) on sites of increasing-type. The profile variability of time-averaged soil moisture content $\left(\mathrm{VP}_{i}\right)$ displays an interesting sequence as follows: waving-type $\quad(0.63)<$ decreasing-type $\quad(1.45)<$ increasing type (2.3).

In addition, mean soil moisture content of individual layer $\left(M_{j}\right)$ increase with increasing of soil depth regardless of sampling time and site (Table 2). Spatial variability across landscape $\left(\mathrm{VS}_{j}\right)$ also shows an increase trend with soil depth (see Table 2), which is consistent with findings by Loague (1992). This may be explained by that the antecedent precipitation across the catchment results in the uniform condition of surface soil moisture, while the spatial hetero- geneity of topography and land use brings in the high degree of landscape variability at deeper depths.

\subsubsection{Correlation analysis}

The DCCA ordination diagram (Fig. 3) illustrates, in an exploratory manner, the relationships between environmental factors and axes as well as relationships between environmental factors and profile distribution of soil moisture content as described above. However, the other useful parts of ordination results for interpretation of the axes are the $R$ (soil, environment) and the intra-set correlation (as shown in Table 3). Whereas intra-set correlation is due to regression of restricted site scores (which are linear combinations of environmental attributes) on environmental attributes, $R$ (soil, env.) is analogous to compound coefficients of multiple regression of axis with all the environmental attributes. It was indicated that the $R$ (soil, env.) values of the first two DCCA axes are significant at the 0.001 level, which implies the strong relation between time-averaged soil 
Table 2

Statistics of profile features for time-averaged soil moisture content at different soil layers on different plots

\begin{tabular}{|c|c|c|c|c|c|c|c|c|c|}
\hline Profile type & Plot & $0-5 \mathrm{~cm}$ & $10-15 \mathrm{~cm}$ & $20-25 \mathrm{~cm}$ & $40-45 \mathrm{~cm}$ & $70-75 \mathrm{~cm}$ & $\operatorname{Mean}\left(M_{i}\right)^{\mathrm{a}}$ & Profile variability $\left(\mathrm{VP}_{\mathrm{i}}\right)^{\mathrm{b}}$ & Profile gradient $\left(G_{i}\right)^{\mathrm{c}}$ \\
\hline \multirow[t]{3}{*}{ Decreasing-type } & 6 & $9.67^{\mathrm{d}}$ & 7.24 & 6.69 & 6.06 & 5.67 & 7.07 & 1.58 & -5.71 \\
\hline & $11 / 12$ & 11.26 & 10.49 & 9.92 & 8.66 & 8.01 & 9.67 & 1.33 & -4.64 \\
\hline & Mean & 10.47 & 8.87 & 8.31 & 7.36 & 6.84 & 8.37 & 1.45 & -5.18 \\
\hline \multirow[t]{5}{*}{ Waving-type } & 3 & 12.41 & 12.18 & 11.80 & 12.95 & 12.20 & 12.31 & 0.42 & 0.77 \\
\hline & 5 & 10.21 & 9.88 & 10.53 & 11.00 & 11.25 & 10.57 & 0.56 & 1.49 \\
\hline & 17 & 15.71 & 15.02 & 16.65 & 15.39 & 17.86 & 16.13 & 1.14 & 3.07 \\
\hline & $3-3$ & 12.31 & 12.58 & 12.79 & 13.28 & 12.39 & 12.67 & 0.39 & 0.11 \\
\hline & Mean & 12.66 & 12.42 & 12.94 & 13.16 & 13.42 & 12.92 & 0.63 & 1.36 \\
\hline \multirow[t]{21}{*}{ Increasing-type } & 1 & 7.79 & 9.23 & 10.63 & 11.72 & 11.96 & 10.27 & 1.75 & 5.96 \\
\hline & 2 & 7.85 & 10.01 & 11.22 & 13.50 & 14.53 & 11.42 & 2.68 & 9.54 \\
\hline & 4 & 11.05 & 13.54 & 15.07 & 15.23 & 17.38 & 14.45 & 2.34 & 9.04 \\
\hline & 7 & 8.38 & 10.28 & 11.47 & 12.42 & 13.35 & 11.18 & 1.94 & 7.10 \\
\hline & 8 & 8.54 & 9.61 & 11.11 & 12.33 & 13.78 & 11.07 & 2.09 & 7.49 \\
\hline & 9 & 8.69 & 9.95 & 10.75 & 12.23 & 14.06 & 11.14 & 2.08 & 7.67 \\
\hline & 10 & 8.49 & 9.39 & 10.51 & 11.84 & 13.90 & 10.82 & 2.13 & 7.73 \\
\hline & 13 & 10.23 & 11.08 & 13.90 & 15.75 & 17.61 & 13.71 & 3.10 & 10.54 \\
\hline & 14 & 14.73 & 15.00 & 16.72 & 17.99 & 20.46 & 16.98 & 2.35 & 8.19 \\
\hline & 15 & 10.66 & 11.83 & 13.32 & 13.95 & 15.94 & 13.14 & 2.03 & 7.54 \\
\hline & 16 & 14.15 & 17.11 & 19.26 & 21.19 & 24.16 & 19.17 & 3.82 & 14.30 \\
\hline & 18 & 12.94 & 14.71 & 15.87 & 17.21 & 19.38 & 16.02 & 2.45 & 9.20 \\
\hline & $1-1$ & 9.74 & 11.59 & 12.55 & 14.13 & 16.44 & 12.89 & 2.54 & 9.57 \\
\hline & $1-2$ & 11.98 & 13.91 & 15.29 & 15.97 & 16.59 & 14.75 & 1.84 & 6.59 \\
\hline & $2-1$ & 7.88 & 9.43 & 10.96 & 12.76 & 14.43 & 11.09 & 2.60 & 9.36 \\
\hline & $3-1$ & 10.07 & 11.02 & 12.50 & 13.30 & 14.15 & 12.21 & 1.66 & 5.83 \\
\hline & $3-2$ & 12.04 & 12.55 & 14.02 & 15.13 & 16.19 & 13.98 & 1.74 & 5.93 \\
\hline & $4-1$ & 9.00 & 10.92 & 11.46 & 13.60 & 14.62 & 11.92 & 2.23 & 8.03 \\
\hline & $4-2$ & 8.93 & 10.69 & 11.64 & 13.04 & 14.23 & 11.71 & 2.05 & 7.57 \\
\hline & $4-3$ & 8.89 & 11.86 & 12.44 & 14.52 & 15.26 & 12.59 & 2.51 & 9.10 \\
\hline & Mean & 10.10 & 11.68 & 13.03 & 14.40 & 15.91 & 13.03 & 2.30 & 8.31 \\
\hline \multirow[t]{2}{*}{ Summary } & $\operatorname{Mean}\left(M_{j}\right)^{\mathrm{e}}$ & 10.52 & 11.58 & 12.66 & 13.67 & 14.83 & 12.65 & 1.69 & 6.21 \\
\hline & Spatial variability $\left(\mathrm{VS}_{j}\right)^{\mathrm{f}}$ & 2.21 & 2.24 & 2.65 & 2.90 & 3.71 & 2.74 & & \\
\hline
\end{tabular}

\footnotetext{
${ }^{\text {a }}$ Mean soil moisture $\left(\mathrm{M}_{\mathrm{i}}\right)$ calculated from Eq. (1).

${ }^{\mathrm{b}}$ From Eq. (6).

${ }^{c}$ From Eq. (10).

${ }^{\mathrm{d}}$ Represents the time-averaged soil moisture $\left(M_{i, j}\right)$ calculated from Eq.(4).

e Represents the mean soil moisture at individual soil layer $\left(M_{j}\right)$ calculated from Eq. (2).

${ }^{f}$ From Eq. (8).
} 
Table 3

Coefficients of correlation between DCCA axes, mean soil moisture, profile features of time-averaged soil moisture and environmental attributes

Axis 1 Axis 2 Mean soil Moisture on plot $i \quad$ Profile type Profile gradient $\left(G_{i}\right)$ Profile variability $\left(\mathrm{VP}_{i}\right)$ $\left(M_{i}\right)$

\begin{tabular}{|c|c|c|c|c|c|c|}
\hline \multicolumn{7}{|l|}{ DCCA ordination axes } \\
\hline Axis 1 & 1.00 & & & & & \\
\hline Axis 2 & 0.99 & 1.00 & & & & \\
\hline \multicolumn{7}{|c|}{ Mean soil moisture content } \\
\hline Mean soil moisture $\left(M_{i}\right)$ & 0.36 & 0.34 & 1.00 & & & \\
\hline \multicolumn{7}{|l|}{ Profile features } \\
\hline Profile type & 0.95 & 0.95 & 0.41 & 1.00 & & \\
\hline Profile gradient $\left(G_{i}\right)$ & 0.94 & 0.93 & 0.56 & 0.92 & 1.00 & \\
\hline Profile variability $\left(\mathrm{VP}_{i}\right)$ & 0.64 & 0.63 & 0.40 & 0.62 & 0.81 & 1.00 \\
\hline \multicolumn{7}{|l|}{ Environmental attributes } \\
\hline Land use & 0.74 & 0.75 & 0.57 & 0.79 & 0.69 & 0.46 \\
\hline Aspect & -0.14 & -0.16 & 0.55 & -0.07 & 0.01 & 0.05 \\
\hline Slope position & 0.25 & 0.25 & -0.45 & 0.18 & 0.15 & 0.29 \\
\hline Landform type & 0.19 & 0.17 & 0.32 & 0.14 & 0.30 & 0.30 \\
\hline Slope shape & -0.07 & -0.05 & 0.13 & 0.02 & 0.01 & 0.11 \\
\hline Slope gradient & -0.28 & -0.27 & -0.19 & -0.22 & -0.32 & -0.32 \\
\hline Relative elevation & 0.20 & 0.19 & -0.38 & 0.13 & 0.10 & 0.23 \\
\hline
\end{tabular}

moisture and environmental attributes. The intra-set correlation will be included in the following cross correlation analysis.

Table 3 gives the coefficients of correlation between DCCA ordination axes, mean soil moisture $\left(M_{i}\right)$, profile features of time-averaged soil moisture content (i.e. profile type, profile gradient $\left(G_{i}\right)$ and profile variability $\left.\left(\mathrm{VP}_{i}\right)\right)$, and environmental attributes (i.e. land use and topography). Among, the correlation between the DCCA axes and the environmental attributes actually are the intra-set correlation quantified by DCCA. For the purpose of discussion, we refer to positive and negative correlation levels between 0 and 0.1 as unrelated, between 0.1 and 0.3 as weak, between 0.3 and 0.4 as moderate, between 0.4 and 0.5 as significant at level of 0.05 , and between 0.5 and 1 as strong (statistically significant at level of 0.01).

The correlation analysis can further provide a quantitative explanation on the result shown in ordination diagram. For example, there is a strong correlation ( $r=0.99$ ) between axes 1 and 2 (see Table 3 ), and both the first two axes are strongly related to the profile distribution type of soil moisture. This, in a quantitative manner, proves that both axes jointly represent the profile characteristics of soil moisture distribution as concluded from DCCA ordination diagram (Fig. 3). The intra-set correlation, or the correlation between each axis and each environmental attribute, also quantifies and proves the dominance of land use as shown in the DCCA ordination diagram. In addition, both axes show strong and positive correlation with profile gradient $\left(G_{i}\right)$ and profile variability $\left(\mathrm{VP}_{i}\right)$.

Not only can we qualitatively separate the types of profile distribution of soil moisture, but also can we use profile gradient of soil moisture content $\left(G_{i}\right)$ as a variable for further determining the intensity and direction of profile gradient of soil water. A negative value of $G_{i}$ shows that gradient direction of soil water is down-layer. There is a potential to promote soil water moving down to lower layer driven by gravity. However, a positive value of $G_{i}$ means that there is a potential to retard soil water moving down. In each case, the greater the absolute values of $G_{i}$, the stronger the vertical redistribution potential of soil water. It was shown in Table 3 that profile gradient $\left(G_{i}\right)$ of soil water displays strong correlation with land use and moderate relation with slope gradient and landform type. However, it displays weak 


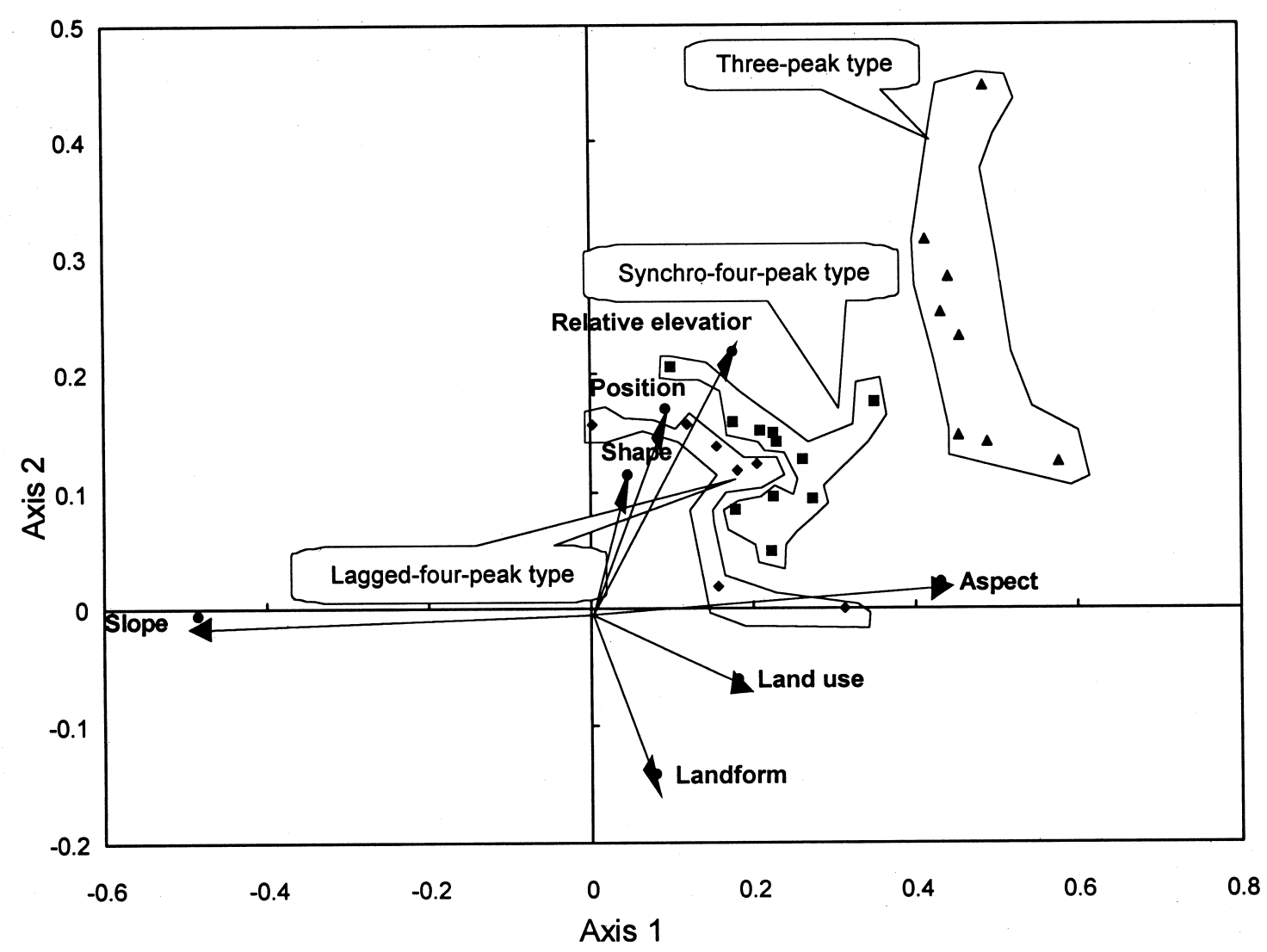

Fig. 5. Ordination diagram resulting from DCCA on layer-averaged soil moisture with environmental attributes.

correlation with slope position and relative elevation, and shows no association with aspect and slope shape.

The profile variability of soil moisture $\left(\mathrm{VP}_{i}\right)$ shows the same relations with environmental factors as profile gradient $\left(G_{i}\right)$ (see Table 3 ).

In addition, mean soil moisture of individual plot $\left(M_{i}\right)$ exhibits statistically significant correlation with profile features (i.e. profile type, profile gradient $\left(G_{i}\right)$ and profile variability $\left.\left(\mathrm{VP}_{\mathrm{i}}\right)\right)$ and several environmental factors (e.g. land use, aspect and slope position) (See Table 3). It also shows moderate relation with landform type and relative elevation, while exhibits weak association with slope gradient and slope shape. Aspect influences solar irradiation and evapotranspiration. Strong and positive correlation between mean soil moisture content of individual plot $\left(M_{i}\right)$ and aspect is consistent with previous findings by Reid (1973), Moore et al. (1988), Famiglietti et al. (1998) and Western et al. (1999). The higher position or relative elevation can foster more soil water draining down and less water coming from upslope. A number of researchers have demonstrated that soil moisture content is inversely proportional to position and relative elevation (Krumbach, 1959; Henninger et al., 1976; Hawley et al., 1983; Robinson and Dean, 1993; Nyberg, 1996; Famiglietti et al., 1998). Moore et al. (1988), Nyberg (1996) and Famiglietti et al. (1998) have also noted a weak correlation between the soil moisture content and slope gradient. A weak correlation between the mean soil moisture content and curvature (slope shape) is consistent with the previous reports by Moore et al. (1988), Famiglietti et al. (1998) and Western et al. (1999). 


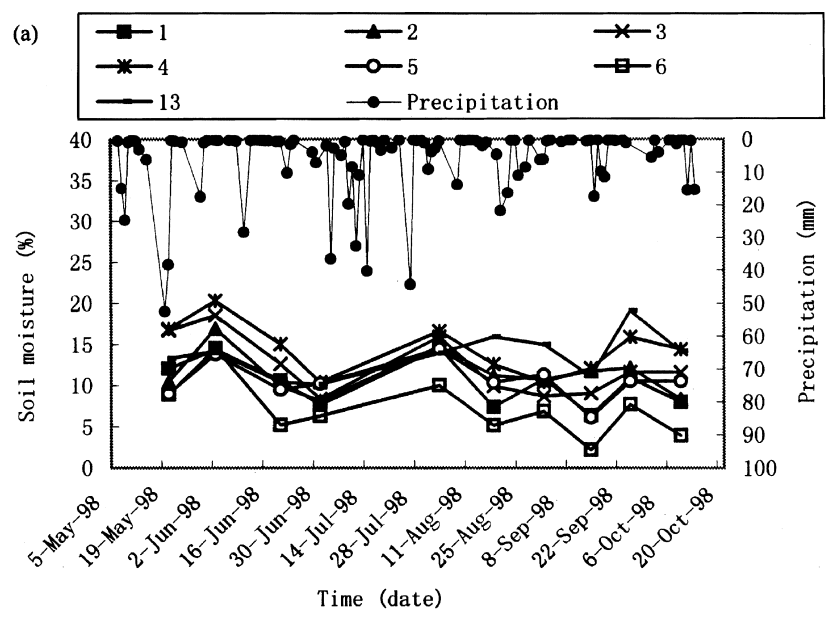

(b)
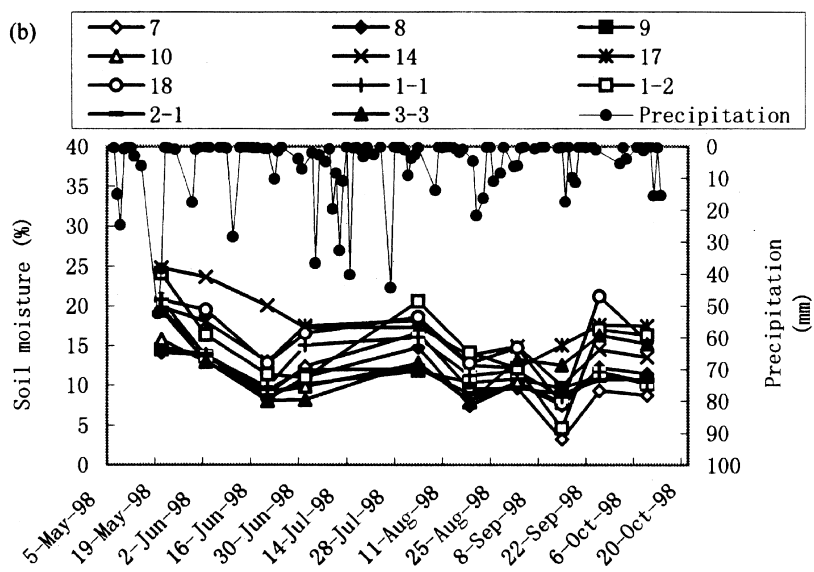

Time (date)

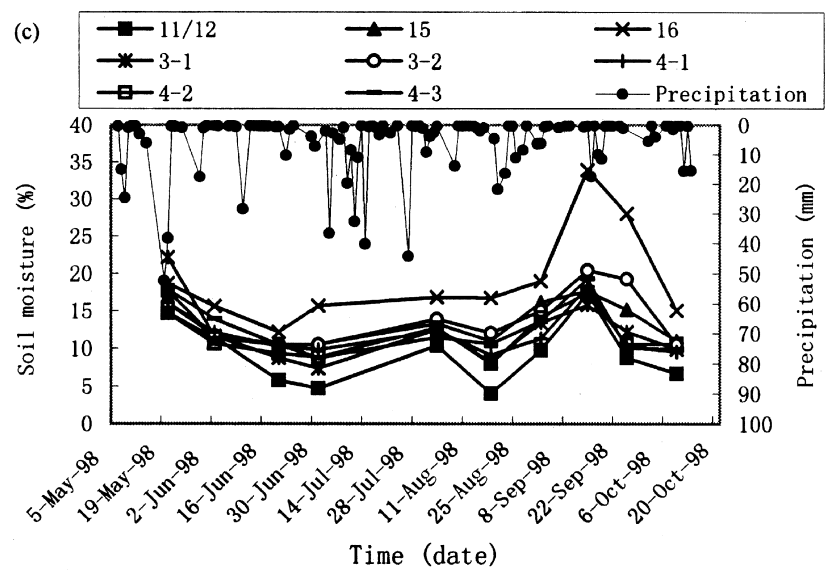

Fig. 6. Temporal dynamics diagram of layer-averaged soil moisture together with the daily precipitation. 
4.2. Temporal dynamics of soil moisture content and its relation to environmental factors

\subsubsection{DCCA ordination diagram and its interpretation}

The DCCA ordination diagram in Fig. 5 shows the relationships of temporal dynamics of layer-averaged soil moisture $\left(M_{i, k}\right)$ with the environmental attributes. The same interpretation of the ordination diagram for profile distribution (Fig. 4) above applies to this diagram (Fig. 5). In Fig.5, the site points and environmental arrows jointly approximate the covariance of soil moisture temporal dynamics with environmental attributes. If one imagines a projected arrow from the origin to each site points, the cosine of an angle between the arrow of a site and that of an environmental attribute approximately quantifies the correlation between the site and environmental attribute. This means that arrows pointing roughly in the same direction indicate high positive correlation, than arrows pointing in the opposite directions imply high negative correlation and that arrows crossing at right angles indicate zero correlation. In addition, the length of arrow indicates how variations in measured sites differ along the environmental gradients. Therefore, the environmental attributes that are highly correlated with points of sites are represented by longer arrows that are closer to the imaged arrows of sites than those for the less important environmental attributes. For example, high correlation with most of the site points is positive for aspect and relative elevation, and is negative for slope gradient.

\subsubsection{General feature of temporal dynamics of layer- averaged soil moisture content}

Two groups of plots in Fig. 5 represent two temporal variation type of layer-averaged soil moisture content $\left(M_{i, k}\right)$, respectively. Three-peak type (Fig. $6 c)$ is located in the right-top hand of Fig. 5. However, Four-peak type (as shown in Fig. 6a and b) is located in the left-bottom hand of Fig. 5. From June to August in 1998, soil moisture changes according with precipitation. For example, the first two peaks of soil moisture content including spring- and summer-peak keep pace with that of precipitation. These two types show distinct difference in September. Three-peak type peaks on 15 September 1998, while four-peak type shows a valley on that date.
The four-peak type can further be divided into two types, i.e. synchro-four-peak type and lagged-fourpeak type (See Figs. 5, 6a and b). The boundary between these two types is not so clear as that between the three-peak type and the four-peak type (Fig. 5), since there is less difference in temporal characteristics between these two types (Fig. 6). Therefore, the division between these two types was based on the DCCA ordination values (Fig. 5) and the temporal features (Fig. 6), especially for the site points near the boundary. Lagged-four-peak type is located in the left-bottom hand of Fig. 5, while synchro-fourpeak type is distributed in the middle part. Main difference of the two types lies in the time when the first peak emerges in spring as shown in Fig. 6a and b. The soil moisture content of synchro-four-peak type peaks synchronized with the rainfall in the middle of May (Fig. 6b), while soil moisture of lagged-four-type emerges as peaks lagged behind the rainfall at the beginning of June (Fig. 6a).

There is a little difference in both the mean $\left(M_{i}\right)$ and temporal variability $\left(\mathrm{VT}_{i}\right)$ of layer-averaged soil moisture between each of the three types. The lagged-four-peak type (average 11.4\%) is slightly drier than both synchro-four-peak (average 13.16\%) and three-peak types (average 13.05\%) (Table 4). The temporal variability of layer-averaged soil moisture $\left(\mathrm{VT}_{i}\right)$ displays a systemic sequence as follows: lagged-four-peak type $(2.98)<$ synchro-four-peak type $(3.46)<$ three-peak type (3.96). This is also obvious as shown in Fig. 6.

The dynamics of mean soil moisture of individual sampling occasion $\left(M_{k}\right)$ shows the same pattern as that of synchro-four-peak type (Table 4).

The spatial variability though landscape $\left(\mathrm{VS}_{k}\right)$ is highest in autumn, followed by spring and is lowest during summer (Table 4 and Fig. 6) when soil moisture $\left(M_{k}\right)$ is at its lowest. In summer, rainfall rather than topographic factors predominates over soil moisture content. Soil moisture is low due to large evapotranspiration although precipitation is large. Hydraulic conductivity is low and lateral redistribution is insignificant. Consequently, soil moisture tends to be uniform across landscape. In autumn and spring, effect of topography on microclimate and phenology (the seasonal pattern of plant growth, e.g. germinate, leaf, blossom, fructify, defoliate, dormancy etc.) and lateral redistribution becomes stronger. Soil moisture 
Table 4

Statistics of temporal features for layer-average soil moisture content at different measurement dates on different plots

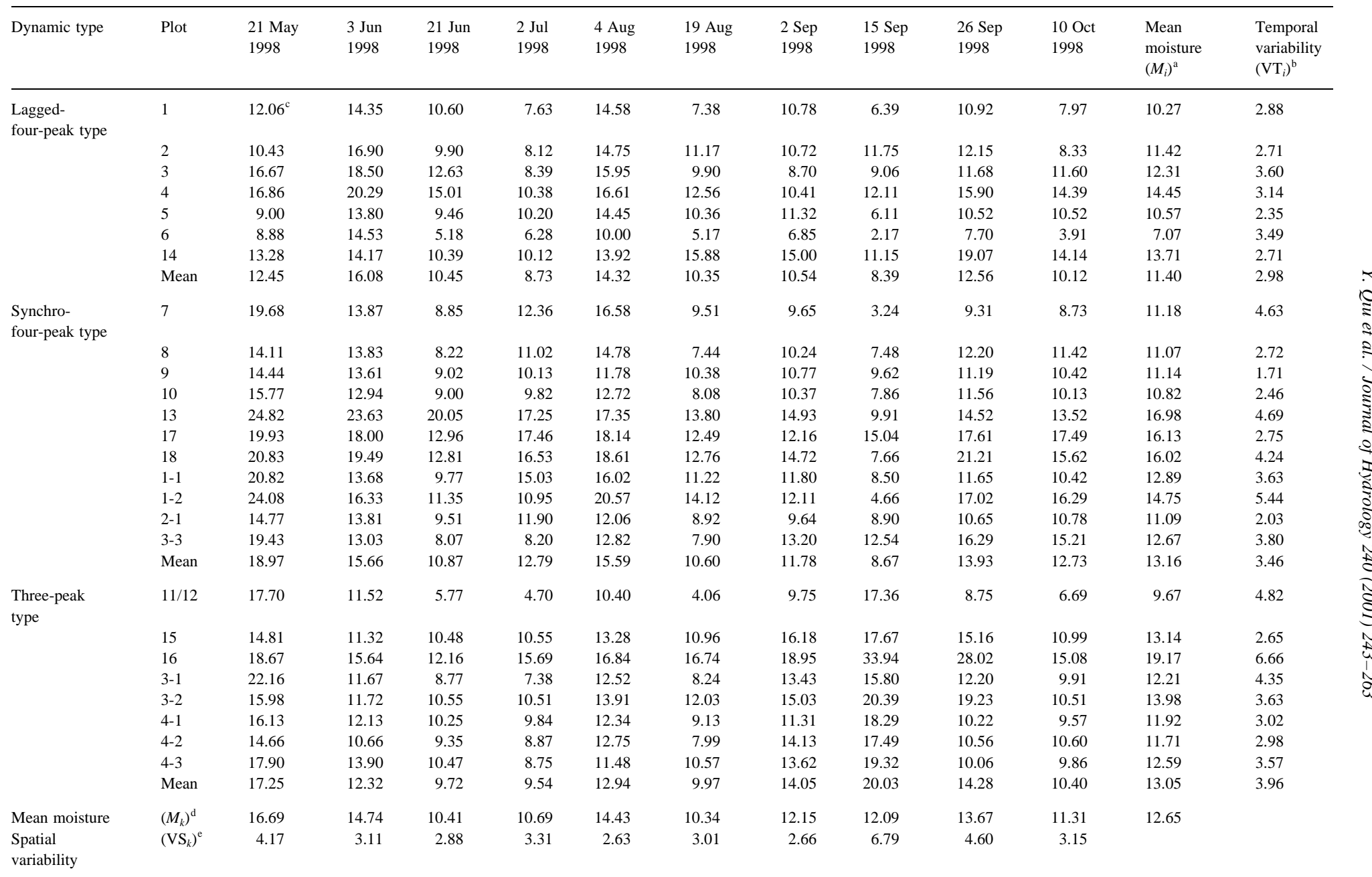

\footnotetext{
${ }^{\mathrm{a}}$ From Eq. (1).

${ }^{b}$ From Eq. (7).

${ }^{c}$ Represents the layer-averaged soil moisture $\left(M_{i, k}\right)$ calculated from Eq. (5).

${ }^{\mathrm{d}}$ Represents the mean soil moisture on individual measurement occasions $\left(M_{k}\right)$ calculated from Eq. (3).

${ }^{\mathrm{e}}$ From Eq. (9).
} 
Table 5

Coefficients of correlation between DCCA axes, mean soil moisture, temporal features of layer-averaged soil moisture and environmental attributes

\begin{tabular}{|c|c|c|c|c|c|}
\hline & Axis 1 & Axis 2 & Mean soil moisture $\left(M_{i}\right)$ & Dynamic type & Temporal variability $\left(\mathrm{VT}_{i}\right)$ \\
\hline \multicolumn{6}{|l|}{ DCCA ordination axes } \\
\hline Axis 1 & 1.00 & & & & \\
\hline Axis 2 & 0.46 & 1.00 & & & \\
\hline \multicolumn{6}{|l|}{ Mean soil moisture content } \\
\hline Mean soil moisture $\left(M_{I}\right)$ & 0.35 & -0.38 & 1.00 & & \\
\hline \multicolumn{6}{|l|}{ Temporal features } \\
\hline Dynamic type & 0.84 & 0.50 & 0.24 & 1.00 & \\
\hline Temporal variability $\left(\mathrm{VT}_{i}\right)$ & 0.26 & 0.15 & 0.50 & 0.34 & 1.00 \\
\hline \multicolumn{6}{|l|}{ Environmental attributes } \\
\hline Land use & 0.20 & -0.13 & 0.57 & 0.25 & -0.08 \\
\hline Aspect & 0.58 & 0.21 & 0.55 & 0.44 & 0.26 \\
\hline Slope position & 0.18 & 0.38 & -0.45 & 0.25 & -0.17 \\
\hline Landform & 0.02 & -0.31 & 0.32 & -0.17 & 0.18 \\
\hline Slope shape & 0.11 & 0.29 & 0.13 & 0.10 & 0.43 \\
\hline Slope gradient & -0.58 & -0.12 & -0.19 & -0.45 & -0.02 \\
\hline Relative elevation & 0.28 & 0.49 & -0.38 & 0.40 & -0.20 \\
\hline
\end{tabular}

content is higher (around 20\%) and almost reaches the field capacity of loess in this area (about 22\%) because of lower evapotranspiration (Yang et al., 1998). Hydraulic conductivity is also higher and lateral redistribution may be more important. Consequently, spatial variation in soil moisture content across landscape $\left(\mathrm{VS}_{i}\right)$ is higher in autumn and spring than in summer. Western et al. (1998) reached a similar conclusion.

\subsubsection{Correlation analysis}

As in the case of analysis of profile features of timeaveraged soil moisture, the $R$ (soil, env.) values of the first two DCCA axes are also significant at the 0.001 level, which implies the strong relation between layeraveraged soil moisture and environmental attributes. In addition, the correlation analysis was used to further quantify the relationships between temporal features of layer-averaged soil moisture and environmental attributes. Table 5 provides the correlation coefficients between DCCA ordination axis, mean soil moisture $\left(M_{i}\right)$, temporal features of layer-averaged soil moisture (i.e. temporal type and temporal variability $\left(\mathrm{VT}_{i}\right)$ ), and environmental attributes. For the purpose of discussion, coefficient is also divided into five classes based on the same standard as that of analysis of profile distribution of soil moisture discussed above.

Based on analysis of correlation coefficients in Table 5, correlation with temporal type of layeraveraged soil moisture is significant and positive for aspect and relative elevation; is significant and negative for slope gradient; is moderate and positive for temporal variability $\left(\mathrm{VT}_{i}\right)$; is weak and positive for mean soil moisture $\left(M_{i}\right)$, slope position, land use and slope shape; is weak and negative for landform. This is consistent with finding from DCCA ordination diagram (Fig. 5). Clearly, the correlation analysis can further quantify the result demonstrated in DCCA ordination diagram.

The temporal variability of soil moisture $\left(\mathrm{VT}_{i}\right)$ shows a strong and positive correlation with mean soil moisture $\left(M_{i}\right)$, and exhibits significant and positive relation with slope shape (see Table 5). However, it displays weak correlation with aspect, slope position, landform type, and relative elevation, and shows no relation with land use and slope gradient. A positive correlation between temporal variability and mean soil moisture is in agreement with previous 
finding by Henninger et al. (1976), while the weak relation between temporal variability and relative elevation is contrary to previous finding by Famiglietti et al. (1998).

\section{Discussion and implications}

\subsection{Mechanistic controls on soil moisture content at Da Nangou Catchment}

The physically meaningful explanations of the results of DCCA of soil moisture in relation to the environmental attributes is central to the importance of this approach to study on soil moisture

\subsubsection{Mechanistic controls on profile distribution of soil moisture}

As noted above, the type of profile distribution of soil moisture content (including decreasing-, waving- and increasing-type) is mainly attributed to land use but not topography. The result indicates that differences in vegetation resulting from different land use types is one of the major factors influencing soil moisture variability (Reynolds, 1970b,c; Ng and Miller, 1980; Hawley et al., 1983; Francis et al., 1986). In addition, two variables (i.e. profile gradient $\left(G_{i}\right)$ and profile variance $\left(\mathrm{Vp}_{i}\right)$ of time-averaged soil moisture) that can further quantify the profile distribution of soil moisture are controlled by land use and are also subject to the influencing of topography. This is a consequence of the following processes.

The decreasing-type of soil moisture mainly results from the effects of land use rather than topography. Both locust tree on site 6 and littleleaf peashrubs on site 11/12 (see Table 1) have deep root systems, most of the roots are distributed at depth of great than $60 \mathrm{~cm}$ typically. Therefore, they consume much soil water at deeper layer $(>60 \mathrm{~cm})$ through strong transpiration, which leads to drier in deeper soil layer (Wang and Li, 1989; Li et al., 1999). Moreover, surfaces of both site 6 and site 11/12 is covered by dense trees and shrubs, surface evaporation is weak and thus soil moisture content in upper soil layer is higher than in lower layer.

The waving-type of soil moisture is also due to land use. Land use type of sites with waving-type is orchard land with exception of site 3 as shown in Table 1. Site 3 covered by some small shrubs and herbs have never been used as cropland, and have just planted with some young trees. In general, fruit trees (such as apple tree and pear tree) whose roots mainly are distributed at soil layer of great than $40 \mathrm{~cm}$ consume soil water in moderate depth. This leads to lower soil moisture content in these layers. Small shrubs and young trees on site 3 have similar root distribution to fruit trees. Difference in type, amount and age of vegetation results in difference in profile distribution characteristic of time-averaged soil moisture content among sites of waving-type.

The increasing-type of profile distribution of soil moisture content (i.e. soil moisture increases with depth) is attributed to land use type, and the impact of topography on soil moisture variability in profile becomes more apparent. Land use type with an increasing type is cropland, fallow land and wasteland (See Table 1). All the fallow lands (i.e. site 2, 1-1, 1-2, 2-1, 3-1) and wasteland (i.e. site 10) were used as cropland only 1-2 years ago, and they are covered by annuals and small shrubs now. Crops, annuals and small shrubs are shallow root plants (typical $<30 \mathrm{~cm}$ ); therefore, soil water in upper-soil is lost through transpiration. Frequent tillage on croplands promotes evaporation in topsoil but prevent soil water in lower soil layer from losing by evaporation. Another explanation is the influence of topography. Sites of increasing-type are distributed in such topographic regime as south facing or west facing, low slope angle, hilltop and high relative elevation. Aspect influences solar irradiation and evapotranspiration, therefore, the lower soil moisture in topsoil is in part attributed to higher evapotranspiration on south- and west-facing slopes (Reid, 1973; Moore et al., 1988; Famiglietti et al., 1998; Western et al., 1999). Moreover, location with lower slope receives more infiltrated water, while higher position foster rapid drainage down during precipitation events (Henninger et al., 1976; Hawley et al., 1983; Robinson and Dean, 1993; Nyberg, 1996; Crave and Gascuel-odux, 1997; Famiglietti et al., 1998). Consequently, soil moisture content is higher at lower soil layer than at upper soil layer. 


\subsubsection{Mechanistic controls on temporal dynamics of soil moisture}

As discussed above, layer-averaged soil moisture $\left(M_{i, k}\right)$ in 1998 displays three types of temporal dynamics, i.e. three-peak type, synchro-four-peak type and lagged-four-peak type. It is obvious that precipitation plays a dominant role over the temporal dynamics of layer-averaged soil moisture content especially during summer, since temporal dynamics of soil moisture loosely mimics that of precipitation (Fig. 6). The layer-averaged soil moisture content $\left(M_{i k}\right)$ generally increases with increasing precipitation depth (Li et al., 1999). However, there is also difference in relationship between temporal changes of soil moisture contents and that of precipitation. The difference becomes apparent during spring and fall, because effects of topography on microclimate and phenology (the seasonal evolution of plant growth, i.e. the stages of plant growth come in a seasonal sequence, such as germination, leaf and blossom) become important.

The main difference between three-peak type and synchro-four-peak type occurs in September 1998, which three-peak type peaks while synchro-fourpeak type dips (see Fig. $6 \mathrm{~b}$ and c). This results from effects of topography (e.g. aspect, slope, and relative elevation) (see Fig. 4), and thus from effects of microclimate and phenology.

Since sites of three-peak type are located in northern/eastern and flat slope with higher elevation, it declines in leaf area index (LAI) of plant, solar irradiation and temperature of both air and ground in September (i.e. the stage of defoliation). Thus, weaker evapotranspiration occurs in September 1998 to give rise to the third peak of soil moisture. After that, evaporation on bare ground becomes strong since the plants had withered. Consequently, layer-averaged soil moisture content tends to decrease in spite of slight increase in precipitation. On the contrary, sites of lagged-four-peak type are located in southern/western aspect on steep slope with lower elevation. The stage of defoliation on these sites is later, so it declines in soil moisture more slowly than that of three-peak type. In September 1998, soil moisture dynamics of this type emerges as a valley resulting from strong evaporation and less precipitation. At the beginning of October, soil moisture of this type shows a peak, as transpiration becomes weak because of decreasing of LAI.
Main difference of synchro-four-peak type and lagged-four-peak type lies in time when the first peak emerges in spring. Soil moisture content of synchro-four-peak type peaks in response to precipitation peak in the middle of May (Fig. 6b), while soil moisture of lagged-four-type emerges as peaks lagged behind peak of precipitation (Fig. 6a). Such phenomenon may be explained as the influence of the topography as follows (see Fig. 5 and Table 5). Since sites of lagged-four-peak type are located in steep slope with lower elevation, both surface and subsurface flows from upslope supplement soil water during and after rain event. Hence, an emerging of peak of soil moisture (the second occasion) lagged behind precipitation peak.

In addition, differences in temporal dynamics of layer-averaged soil moisture content between threepeak type and lagged-four-peak type as shown in Fig. 6a and c can also be explained by the influences of topography.

\subsection{Implications}

The potential infiltration rate of any area is determined primarily by the antecedent soil moisture level (Hawley et al., 1983). For the purpose of accurately modeling, it is necessary for considering all aspects of soil moisture regime such as the soil moisture level (e.g. $M_{i}$ ), the profile features and the temporal features of antecedent soil moisture content. Only considering the level of soil moisture for modeling may lead to error.

Variation in topography, land use and soil attribute all affect the distribution of soil moisture content. There were many quantitative indices of topography which was developed as a basis for predicting soil moisture regime. However, these indices have performed well in some circumstances but poorly in many others (Famiglietti et al., 1998; Western et al., 1999). Our study in the Loess Plateau of China in 1998 indicates that different variables that describe different aspects of soil moisture regime are correlated to different environmental factors (see Tables 3 and 5). For example, the profile distribution of soil moisture content is jointly influenced by both land use and topography, while the temporal dynamics is controlled by some terrain indices.

Land management models are designed to evaluate 
the hydrologic effects of changes in land use and topography. In most situations, simple rather than accurate estimates of soil moisture is necessary for this type of model. Therefore, identification of type of soil moisture features (e.g. profile type and temporal type) and study on relationships between these types and environmental factors (e.g. land use and topography) can provide a simple and applicable approach to land management.

\section{Conclusions}

Variation in profile characteristics and temporal dynamics of soil moisture content were studied at 26 locations in Da Nangou catchment $\left(3.5 \mathrm{~km}^{2}\right)$ in the loess area of China. Soil moisture measurements were performed biweekly at five depths in the soil profile $(0-5 \mathrm{~cm}, 10-15 \mathrm{~cm}, 20-25 \mathrm{~cm}, 40-45 \mathrm{~cm}$ and 70-75 cm) from May to October 1998 using Delta-T theta probe. The types of both profile and seasonal dynamics distributions of soil moisture were identified from DCCA. In addition, the dominant influences on soil moisture variability were inferred by DCCA and correlation analyses.

Three types of profile distribution of time-averaged soil moisture (i.e. decreasing-type, waving-type and increasing-type) were identified by DCCA. It was indicated through DCCA and cross correlation analysis that the profile type of time-averaged soil moisture as well as additional quantitative indices e.g. profile gradient $\left(G_{i}\right)$ and profile variability $\left(\mathrm{VP}_{i}\right)$ of timeaveraged soil moisture are correlated to each other. It was concluded that different profile features of soil moisture are influenced by different environmental factors. The profile type of soil moisture content is only significantly correlated to land use. Both the profile gradient $\left(G_{i}\right)$ and the profile variability $\left(\mathrm{VP}_{i}\right)$ are dominated by land use and are influenced by topography (e.g. landform type and slope gradient). The profile gradient of soil water $\left(G_{i}\right)$ is a new index developed in this study to further quantify the direction and intensity of profile soil water distribution, and thus to determine the lateral and vertical redistribution of soil water.

Three types of temporal dynamics of layeraveraged soil moisture (i.e. three-peak type, synchro-four-peak type and lagged-four-peak type) are separated by DCCA. We found that the temporal dynamics type and temporal variability $\left(\mathrm{VS}_{i}\right)$ of layeraveraged soil moisture are related to each other and both two indices are controlled by topography rather than by land use. The temporal dynamic type of layeraveraged soil moisture shows significant correlation with relative elevation, slope gradient, and aspect, while the temporal variability $\left(\mathrm{VS}_{i}\right)$ displays a significant relation with slope shape.

The mean soil moisture $\left(M_{i}\right)$ is related to both the profile and dynamics features of soil moisture content, and is controlled by both the land use and topography (e.g. aspect, slope position, slope gradient and relative elevation).

The spatial variability of soil moisture across landscape varies with both soil depths and temporal evolution. The spatial variability of time-averaged soil moisture $\left(\mathrm{VS}_{j}\right)$ increases with increasing of soil depth. While, the spatial variability of layer-averaged soil moisture $\left(\mathrm{VS}_{k}\right)$ is highest in autumn followed by spring and is lowest during summer.

\section{Acknowledgements}

The project was supported by the National Natural Science Foundation of China (Contract No. 49725101) and INCO-DC of European Commission (Contract No. ERBIC18CT970158). The authors wish to acknowledge the member of project team for measuring the soil moisture in the field together and also the referees of this paper for their useful suggestions.

\section{References}

Bárdossy, A., Lehmann, W., 1998. Spatial distribution of soil moisture in a small catchment. Part I: geostatistical analysis. Journal of Hydrology 206, 1-5.

Bell, K.R., Blanchard, B.J., Schmugge, T.J., Witczak, M.W., 1980. Analysis of surface moisture variations within large field sites. Water Resources Research 16 (4), 796-810.

Burt, T.P., Butcher, D.P., 1985. Topographic controls of soil moisture distributions. Journal of Hydrology 36, 469-486.

Crave, A., Gascuel-odux, C., 1997. The influence of topography on the time and space distribution of soil surface water content. Hydrological Processes 11, 203-210.

Famiglietti, J.S., Rudnicki, J.W., Rodell, M., 1998. Variability in surface moisture content along a hillslope transect: Rattlesnake Hill, Texas. Journal of Hydrology 210, 259-281. 
Francis, C.F., Thomes, J.B., Romero Diaz, A., Lopez Bermudez, F., Fisher, G.C., 1986. Topographic control of soil moisture, vegetation cover and land degradation in a moisture stressed Mediterranean environment. Catena 13, 211-225.

Fu, B., Wang, J., Ma, K., 1999. Effect of land use on soil water in loess hill area. Bulletin of National Natural Science Foundation of China 13 (4), 225-227 (in Chinese).

Fu, B., 1989. Soil erosion and its control in the Loess Plateau of China. Soil Use and Management 5, 76-82.

Fu, B., Gulinck, H., 1994. Land evaluation in area of severe erosion: the Loess Plateau of China. Land Degradation \& Rehabilitation 5 (1), 33-40.

Fu, B., Chen, L., 2000. Agricultural landscape spatial pattern analysis in the semi-arid hill area of the Loess Plateau, China. Journal of Arid Environments 44 (3), 291-303.

Fu, B., Chen, L., Ma, K., Zhou, H., Wang, J., 2000. The relationships between land use and soil conditions in the hilly area of the Loess Plateau in northern Shaanxi, China. Catena 36, 69-78.

Grayson, R.B., Western, A.W., 1998. Towards area estimation of soil water content from point measurements: time and space stability of mean response. Journal of Hydrology 207, 68-82.

Grayson, R.B., Western, A.W., Chiew, F.H.S., Bloschl, G., 1997. Preferred states in spatial soil moisture patterns: local and nonlocal controls. Water Resource Research 33, 2897-2908.

Hawley, M.E., Jackson, T.J., McCuen, R.H., 1983. Surface soil moisture variation on small agricultural watersheds. Journal of Hydrology 62, 179-200.

Henninger, D.L., Peterson, G.W., Engman, E.T., 1976. Surface soil moisture within a watershed: Variations, factors influencing, and relationships to surface runoff. Soil Science Society of America Journal 40, 773-776.

Hill, M.O., Gauch, H.G., 1980. Detrended correspondence analysis, an improved ordination technique. Vegetatio 42, 47-58.

Krumbach Jr, A.W., 1959. Effects of microrelief on distribution of soil moisture and bulk density. Journal of Geophysical Research 64, 1587-1590.

Li, H., Wang, M., Chai, B., 1999. Characteristics of soil water in Robinia Pseudoacacia population. Journal of Soil Erosion and Soil and Water Conservation 5 (6), 6-10 (in Chinese).

Loague, K., 1992. Soil water content at R-5. Part 1. Spatial and temporal variability. Journal of Hydrology 139, 233-251.

McBratney, A.B., Webster, R., 1981. Spatial dependence and classification of soil along a transect in north-east Scotland. Geoderma 26, 63-82.

Moore, I.D., Burch, G.J., Mackenzie, D.H., 1988. Topographic effects on the distribution of surface soil water and the location of ephemeral gullies. Transactions of the American Society of Agriculture Engineering 31, 1098-1107.

$\mathrm{Ng}$, E., Miller, P.C., 1980. Soil moisture relations in the southern California chaparral. Ecology 61 (1), 98-107.

Nyberg, L., 1996. Spatial variability of soil water content in the covered catchment of Gardsjon, Sweden. Hydrological Processes 10, 89-103.

Odeh, I.O.A., Chittleborough, D.J., McBratney, A.B., 1991. Elucidation of soil-landform interrelationships by canonical ordination analysis. Geoderma 49, 1-32.

Owe, M., Jones, E.B., Schmugge, T.J., 1982. Soil moisture variation patterns observed in Hand Country, South Dakota. Water resources Bulletin 18, 949-954.

Qiu, Y., Zhang, J., 2000. The ordination axes clustering based on Detrended Canonical Correspondence Analysis ordination and its application to the analysis of the ecological gradients of plant communities in Bashuigou catchment, Guandi Mountain. Acta Ecologica Sinica 20 (2), 199-206 (in Chinese).

Reid, I., 1973. The influence of slope orientation upon the soil moisture regime, and its hydrogeomorphological significance. Journal of Hydrology 19, 309-321.

Reynolds, S.G., 1970a. The gravimetric method of soil moisture determination. I: A study of equipment, and methodological problems. Journal of Hydrology 11, 258-273.

Reynolds, S.G., 1970b. The gravimetric method of soil moisture determination. II: Typical required sample size and methods of reducing variability. Journal of Hydrology 11, 274-287.

Reynolds, S.G., 1970c. The gravimetric method of soil moisture determination. III: An examination of factors influencing soil moisture variability. Journal of Hydrology 11, 288-300.

Robinson, M., Dean, T.J., 1993. Measurement of near surface soil water content using a capacitance probe. Hydrological Processes 7, 77-86.

Song, G., Li, L., Guo, F., Zhao, M., 1989. Land classification of experiment and exemplary areas on the Loess Plateau, Memoir of Northwestern Institute of Soil and Water Conservation. Academia Sinica and Ministry of Water Resources 10, 1-13 (in Chinese).

Ter Braak, C.J.F., 1985. Correspondence analysis of incidence and abundance data: properties in terms of unimodal response model. Biometrika 41, 859-873.

Ter Braak, C.J.F., 1986. Canonical correspondence analysis: a new eigenvector technique for multivariate direct gradient analysis. Ecology 67, 1167-1179.

Ter Braak, C.J.F., 1987. Ordination. In: Jongman, R.H.J., Ter Braak, C.J.F., Van Tongeren, O.F.R. (Eds.). Data Analysis in Community and Landscape Ecology. Pudoc, Wageningen, pp. 91-173.

Ter Braak, C.J.F., 1988. CANOCO - A Fortran Program for Canonical Community Ordination by [partial] [detrended] [canonical] Correspondence Analysis, Principal Components Analysis and Redundancy Analysis (Version 2.1). Agricultural Mathematics Group, Wageningen, Netherlands.

Wang, M., Li, H., 1989. Study on soil water ecological environment of artificial Caragana Korshinskii bushwood, Memoir of Northwestern Institute of Soil and Water Conservation. Academia Sinica and Ministry of Water Resources 10, 155-160 (in Chinese).

Western, A.W., Blöschl, G., Grayson, R.B., 1998. Geostatistical characteristics of soil moisture patterns in the Tarrawarra catchment. Journal of Hydrology 205, 20-37.

Western, A.W., Grayson, R.B., 1998. The Tarrawarra data set: soil moisture patterns, soil characteristics, and hydrological flux measurements. Water Resources Research 34 (10), 2765-2768.

Western, A.W., Grayson, R.B., Bloschl, G., Willgoose, G.R., McMahon, T.A., 1999. Observed spatial organization of soil moisture and its relation to terrain indices. Water Researces Research 35 (3), 797-810. 
Yang, W., Shao, M., Peng, X., 1998. Study on the relationships between the environment drought and the loess soil water on Loess Plateau. Science in China D 28 (4), 357-365 (in Chinese).

Zhang, J., Oxley, R.R.B., 1994. A comparison of three methods of multivariate analysis of upland grasslands in North Wales. Journal of Vegetation Science 5, 71-76.

Zhuang, J., 1989. About the soil water research in China in the recent four decades. Acta Pedologica Sinica 26 (3), 241-248 (in Chinese). 